\title{
A COMPARATIVE STUDY OF INSULIN RESISTANCE IN OFFSPRINGS OF TYPE 2 DIABETES MELLITUS AND NON DIABETIC PATIENTS, A ONE YEAR CROSS SECTIONAL HOSPITAL BASED STUDY
}

Arathi Darshan, Vikas Patil, Yeshvant G,

\section{HOW TO CITE THIS ARTICLE:}

Arathi Darshan, Vikas Patil, Yeshvant G "A comparative study of Insulin resistance in Offsprings of Type 2 Diabetes Mellitus and Non Diabetic Patients". Journal of Evolution of Medical and Dental Sciences 2013; Vol2, Issue 41, October 14; Page: 7827-7833.

OBJECTIVE: To assess the insulin resistance in offspring's of type 2 diabetes mellitus patients, with off springs of non-diabetic patients. METHODOLOGY: The study included offspring's of 30 diabetic and 30 non-diabetic patients with a proper clinical examination according to predesigned and pretested proforma. Mean age, insulin levels, Homeostasis model assessment-insulin resistance (HOMA-IR) and BMI of the two groups were compared using unpaired ' $t$ ' test. Chi - square test and Kruskal Wallis test were used to test the association between two or more variables in case of frequency distribution. RESULTS: It was observed that the offspring's in case group had higher insulin levels compared to control group. Insulin resistance was found to be $48.5 \%$ in case group and $19.4 \%$ in control group which was considered is statistically significant $(p=0.009)$. Insulin resistance was seen in $47.05 \%$ offspring's whose fathers were a diabetic, $41.6 \%$ offspring's whose mother were a diabetic and $66.6 \%$ offspring's had history of both parents being diabetic. However, the $p$ value was not statistically significant $(p=0.597)$.

KEY WORDS: Insulin resistance, Offspring's, Hypertension and Dyslipidemia.

INTRODUCTION: Asian Indians have an insulin resistant phenotype of obesity characterized by lean body mass index (BMI), high upper body obesity and high body fat percentage which confers a high risk of diabetes and cardiovascular diseases (CVD) in them ${ }^{9}$.

Insulin resistance is a multifaceted syndrome responsible for future development of type 2 diabetes, obesity, hypertension, dyslipidemia and atherosclerotic CVDs ${ }^{10,11}$. Prospective studies have shown that, insulin resistance predates the onset of type 2 diabetes by 10 to 12 years. There has also been a debate as to whether insulin resistance is the primary defect that precedes $\beta$-cell failure in the evolution of hyperglycemia in type 2 diabetes or vice versa. Obesity, especially visceral abdominal obesity, contributes to the development of insulin resistance, which may underlie a number of manifestations and cardiovascular complications of diabetes and the metabolic syndrome.

Anthropometry, plasma glucose and lipid profile including total cholesterol, high density lipoprotein (HDL) cholesterol and fasting triglycerides are routinely measured in screening procedures for diabetes or CVD. Plasma insulin is not routinely measured in most clinical laboratories. Insulin resistance is an important component of the metabolic syndrome and is likely to show an association, with other components of the syndrome9.

First degree relatives, of people with type 2 diabetes have an increased risk of developing the disease, compared with people without diabetes heredity. They show signs of insulin resistance and insufficient insulin secretion despite normal glucose tolerance. Early prevention of diabetes could be of great importance in these individuals. 
The present study was undertaken to compare the insulin resistance in offspring's of type 2 diabetic and non-diabetic parents.

RESEARCH DESIGN AND METHODS: The sample size of 30 cases and 30 controls were randomly selected on account of previous literature. This was a cross sectional study and the power of the study was not compromised with the sample size. All patients presenting with and fulfilling the inclusion criterion were included in this study after obtaining informed written consent (Annexure-I). Oral glucose tolerance test was performed according to WHO criteria and patients with normal glucose tolerance were included in the study.

Fasting blood sample was drawn for measuring plasma insulin levels. Homeostasis model assessment was calculated as;

\section{Fasting Insulin $m U / L X$ Fasting plasma glucose $m$ mol/L \\ 22.5}

Further, insulin resistance was compared in both the groups. Subjects also underwent other investigations like fasting lipid profile.

STATISTICAL METHODS: Mean age, insulin levels, Homeostasis model assessment-insulin resistance (HOMA-IR) and BMI of the two groups were compared using unpaired' $t$ ' test. Chi square test and Kruskal Wallis test were used to test the association between two or more variables in case of frequency distribution. Correlation co-efficient was used to find the association between insulin and other variables. A p value of less than 0.05 was considered as significant.

RESULTS: In the present study, male subjects comprised of $17(48.6 \%)$ in case group and 16 (44.4\%) in control group, female subjects comprised 18 (51.4\%) in case group and 20 (55.6\%) in control group. There was no difference in the sex distribution of two groups.

Most of the subjects were in age group 21 to 25 (In case group 34.3\%, in control group $33.3 \%$ ) and age group more than 40 had the least number of subjects (In case group 5.7\%, in control group 5.6\%). There was no difference in the age distribution of two groups.

The mean age in case group was $25.90 \pm 6.71$ years and $26.10 \pm 7.72$ years in control group ( $p=0.883$ ). The mean BMI in case group was $23.20 \pm 2.79 \mathrm{~kg} / \mathrm{m}^{2}$ and $22.20 \pm 3.03 \mathrm{~kg} / \mathrm{m}^{2}$ in control group ( $p=0.506)$. Hence the mean age and BMI was comparable between the two groups. The mean BMI was maximum in age group more than 40 years $(26.10 \pm 1.31 \mathrm{~kg} / \mathrm{m} 2)$ and least in age group of 15 to 20 years $\left(21.7 \pm 2.55 \mathrm{~kg} / \mathrm{m}^{2}\right)$. There was no difference of mean BMI in various age groups, statistically as calculated by Kruskal Wallis Test $(\mathrm{p}=0.101)$.

The mean insulin level in case group was $23.7 \pm 19.77 \mathrm{mU} / \mathrm{L}$ and in control group was $9.90 \pm$ $7.42 \mathrm{mU} / \mathrm{L}$. This difference between two groups was statistically significant $(\mathrm{p}=0.000)$. with no difference in insulin levels statistically, between $19.9 \pm 21.0 \mathrm{mU} / \mathrm{L}$ and in females was $13.9 \pm 10.16$ $\mathrm{mU} / \mathrm{L} .(\mathrm{p}=0.120)$.

However, statistically there was no difference in the insulin levels in various age groups. with mean insulin level was maximum in 26 to 30 year age group $(19.30 \pm 11.59 \mathrm{mU} / \mathrm{L})$, and 
least in 31 to 35 years age group $(7.40 \pm 4.33 \mathrm{mU} / \mathrm{L})(\mathrm{p}=0.531)$. The mean HOMA-IR index in case group was $5.80 \pm 4.81$ and in control group was $2.20 \pm 1.63$. This difference was statistically significant $(\mathrm{p}=0.000)$.

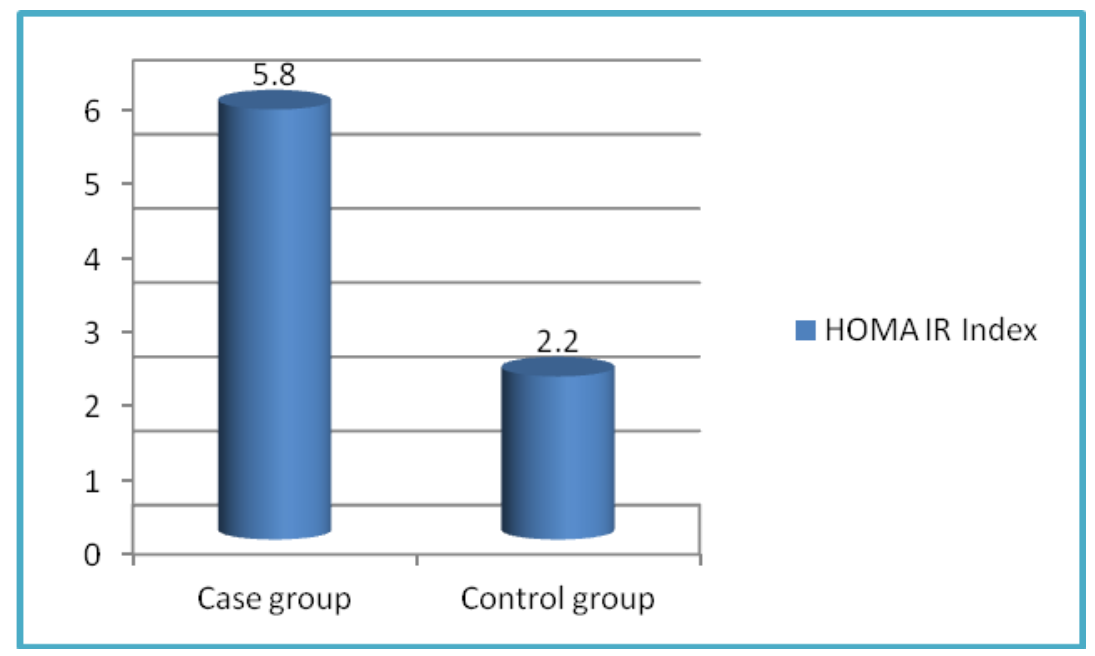

Figure 1:- Homa IR index

The mean HOMA-IR index in males was $4.60 \pm 5.08$ and in females it was $3.00 \pm 2.29$. There was no statistically significant difference in HOMA-IR index between males and females $(\mathrm{p}=0.096)$. The mean HOMA-IR was found to be highest in 15 to 20 years age group (4.70 \pm 4.57$)$ and least in 31 to 35 years age group (1.60 2.84). However statistically, there was no difference in HOMA-IR index in various age groups $(\mathrm{p}=0.616)$.figure 2 :-

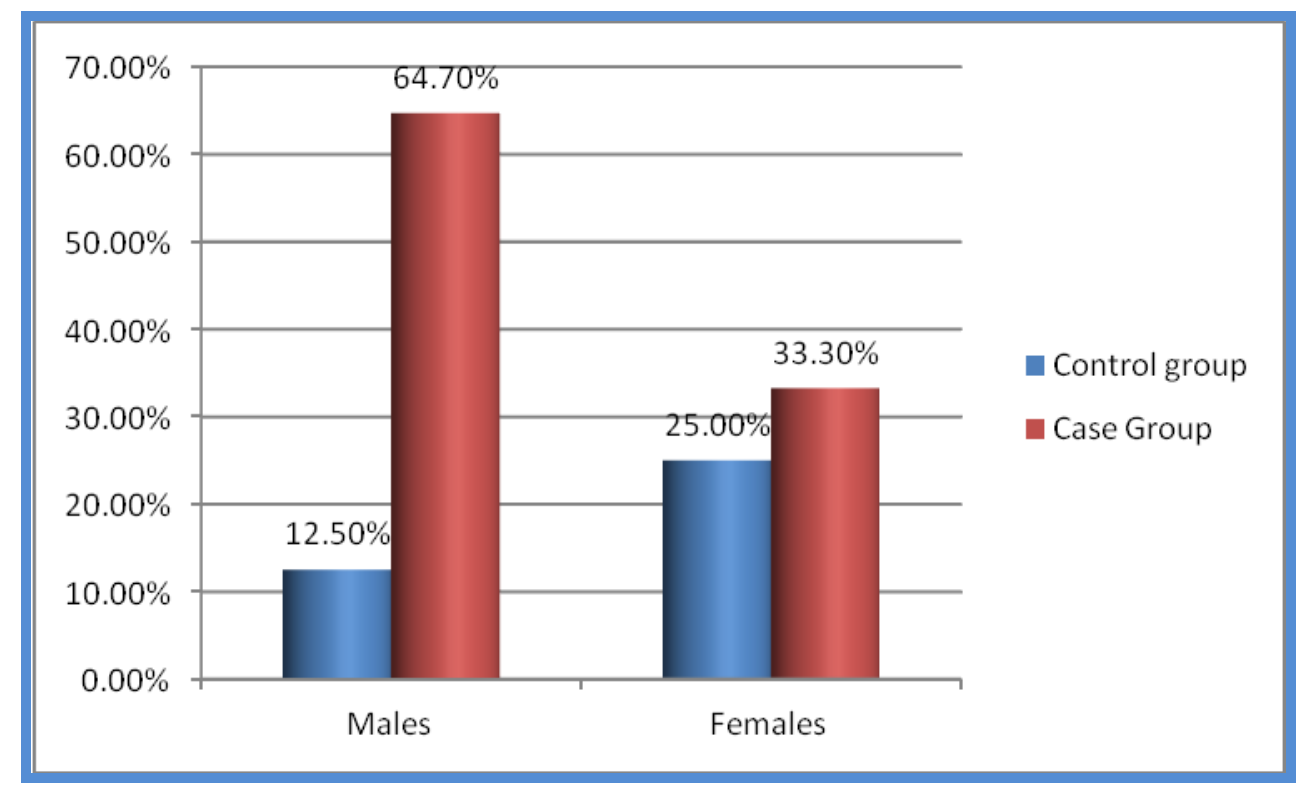

Figure 2:- Homa RX Index between males and females 
In the present study, as in the figure no 3, insulin resistance was found in $48.5 \%$ in case group and $19.4 \%$ in control group. This difference was statistically significant $(\mathrm{p}=0.009)$. Insulin resistance was seen in $64.7 \%$ male offspring's in case group, when compared to $12.5 \%$ offspring's in control group. Insulin resistance was seen in $33.3 \%$ female offspring's in case group, when compared to $25 \%$ offspring's in control group.

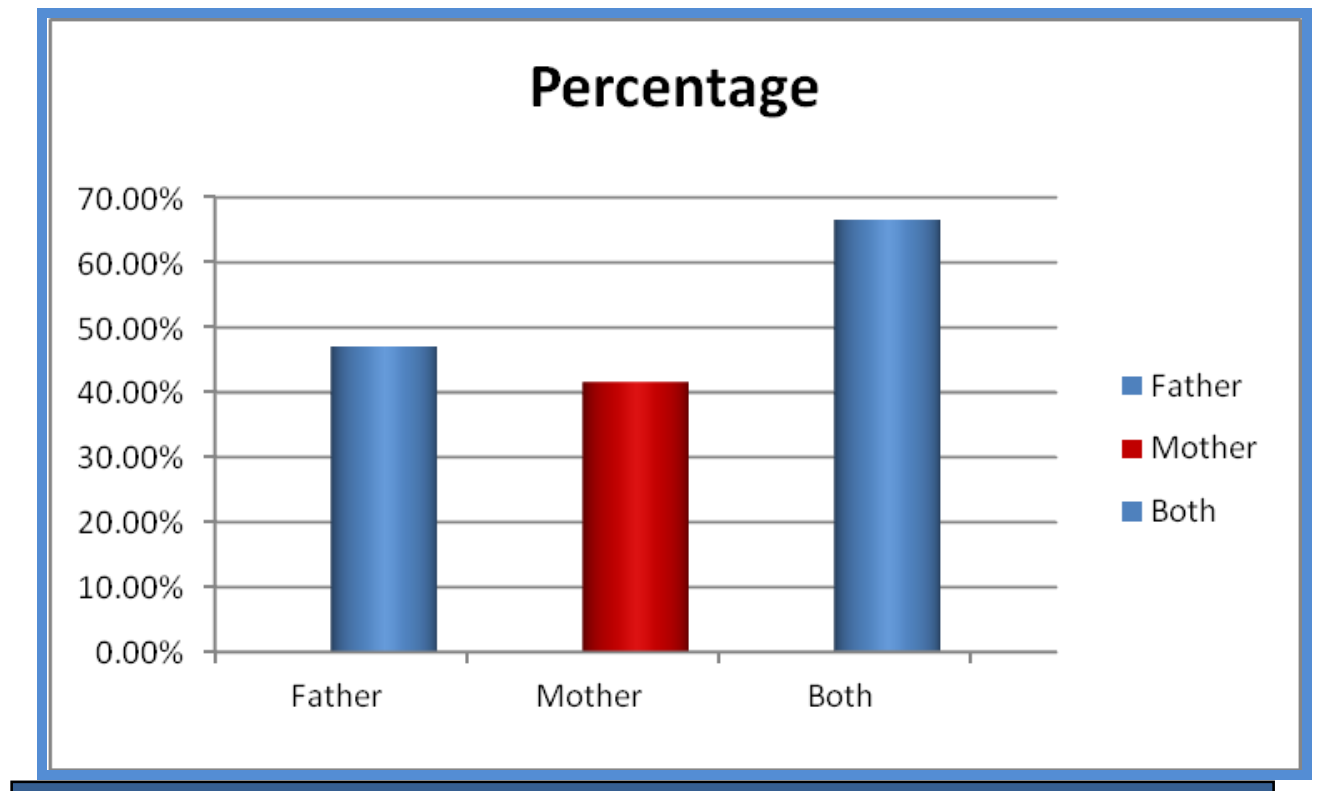

Figure 3: Percentage of insulin resistance

insulin resistance was seen in $47.05 \%$ offspring's whose father was a diabetic, $41.6 \%$ offspring's whose mother was a diabetic and $66.6 \%$ offspring's had history of both parents being diabetic. However, the $p$ value was not statistically significant $(p=0.597)$.

DISCUSSION: The determination of insulin resistance in offspring's of type 2 diabetics has a great clinical and epidemiological importance. Insulin resistance not only puts them at a high risk of developing frank diabetes in future but it has also has been associated with a number of clinical and metabolic abnormalities ${ }^{10}$.

The present study comprised of 35 offspring's of type 2 diabetics (case group) and 36 offspring's of non-diabetics (control group). The total subjects in present study were 71 . Out of which 33 were males and 38 were females.

The case group comprised offspring's of patients, diagnosed to have diabetes after 30 years of age and they were not on any drugs believed to alter plasma glucose levels. The control group, comprised offspring's of non-diabetic individuals.

This was in accordance with a study done in 2005, which evaluated insulin resistance in 172 first degree relatives and 178 controls ${ }^{10}$. Most of the subjects in the present study were between 15-30 years of age, who comprised $82.9 \%$ of sample size in case group and $72.2 \%$ of sample size in control group. The mean age of the subjects in the present study, was $25.9 \pm 6.71$ years in case group and $26.1 \pm 7.72$ years in control group $(\mathrm{p}=0.883)$. 
A cohort study done in Chennai in 2005, studied insulin resistance and serum triglycerides in age and BMI matched groups 9 . Another study in 2003, compared insulin resistance in 17 lean offspring's whose parents had type 2 diabetes with 17 age, sex and BMI matched subjects, without family history of diabetes as controls ${ }^{10}$. The mean fasting insulin levels in the present study were higher in normoglycemic offspring's of diabetic parents $(23.7 \pm 19.7 \mathrm{mU} / \mathrm{L})$ than the corresponding values in controls $(9.9 \pm 7.42 \mathrm{mU} / \mathrm{L})$. This was statistically significant $(\mathrm{p}=0.000)$, indicating that there was hyperinsulinemia in offspring's of diabetic parents.

A study in 2006, found mean insulin levels of $14 \mathrm{mU} / \mathrm{L}$ in Asian Indian men and $10.5 \mathrm{mU} / \mathrm{L}$ in Asian Indian women ${ }^{6}$. The present study, showed comparable insulin levels in all age groups $(\mathrm{p}=0.531)$.

Various studies are used for measurement of insulin resistance. Euglycemic insulin clamp test done for measuring insulin resistance is regarded as gold standard in research. Because of infeasibility of this test, various studies across the globe have regarded homeostasis model assessment (HOMA) method to be gold standard, for measuring insulin resistance in clinical practice and population based research studies ${ }^{7}$. It had been demonstrated that, there was a strong positive correlation, between HOMA-IR and Euglycemic insulin clamp-IR in type 2 diabetic subjects $^{8.14}$. So in the present study, HOMA-IR has been taken as standard method, for measuring insulin resistance.

The HOMA-IR cut off point for diagnosis of insulin resistance was taken as 3.2 in the present study9. In this study, the mean HOMA-IR index was higher in normoglycemic offspring's of diabetic parents $(5.8 \pm 4.81)$ than the corresponding values in controls $(2.2 \pm 1.63)$. This was statistically significant $(\mathrm{p}=0.000)$, indicating a high risk of insulin resistance, in offspring's of diabetic parents.

A study in Poland, in the year 2003, found offspring's of type 2 diabetic parents were insulin resistant $(\mathrm{p}<0.005)^{10}$. Another study found, mean HOMA-IR of $7.462 \pm 5.218$ in first degree relatives of diabetics compared to HOMA-IR $4.335 \pm 2.279$ in first degree relatives of non-diabetics ${ }^{10}$.

Mean HOMA-IR in male subjects in the present study, was $4.6 \pm 5.08$ and $3.0 \pm 2.29$ in female subjects. There was no statistically significant difference in HOMA-IR index between the two groups.

A study done in 2006 found, mean HOMA-IR of 3.29 in Asian Indian men and mean HOMAIR of 2.3 in Asian Indian women 6 . In the present study, HOMA-IR index was comparable in all age groups $(\mathrm{p}=0.616)$.

In the present study, five parents in the case group, that is five diabetic parents, had two offspring's each. The insulin levels were comparable in these offspring's $(p=0.172)$. Similarly four parents in control group had two offspring's each and one had three offspring's. The insulin levels were comparable in these offspring's also ( $\mathrm{p}=0.361)$.

In the present study, insulin resistance was calculated by HOMA-IR and it was found that insulin resistance in normoglycemic offspring's of case group was $48.5 \%$, when compared to that of control group (19.4\%). This was statistically significant $(\mathrm{p}=0.009)$. Hence, risk of insulin resistance was more in the case group compared to control group.

A study of 154 healthy normoglycemic first degree relatives of type 2 DM patients in 1999, showed the prevalence of insulin resistance to be $40 \%{ }^{64}$.Another study of 1,988 normoglycemic relatives of type 2 DM patients of age 35 to 70 years in 2001, showed the prevalence of insulin 
resistance as $25 \%{ }^{12}$. A study done in Lucknow in 2003 , showed the prevalence of insulin resistance, in normoglycemic first degree relatives as $30.2 \%$, as measured by HOMA-IR index ${ }^{10}$.

The higher percentage of insulin resistance, in the present study, was probably due to the reason that, only offspring's were taken as study subjects. Whereas, other studies were done in first degree relatives (siblings and offspring's).

This study, also compared insulin resistance in offspring's of whose either father or mother or both were diabetic. Insulin resistance, was seen in 47.05\% offspring's (8 out of 17) whose father was a diabetic, $41.6 \%$ (5 out of 12) offspring's, whose mother was a diabetic and $66.60 \%$ (4 out of 6) offspring's whose both parents were diabetic. However, this was not statistically significant $(\mathrm{p}=0.597)$.

The present study, also studied association between insulin levels with triglycerides and triglyceride/HDL ratio. Correlation co-efficient, of 0.528 was found between insulin levels and triglycerides $(\mathrm{p}=0.000)$ and 0.381 between insulin levels and triglyceride/HDL ratio $(\mathrm{p}=0.001)$. Hence fasting hyperinsulinemia was associated with fasting hypertriglyceridemia.

The association, between insulin levels and mean blood pressure in the subjects was studied and a correlation coefficient of 0.495 was observed, between the two. This was statistically significant $(\mathrm{p}=0.000)$. Many subjects with hyperinsulinemia were in pre-hypertensive group.

A study done in African Americans, showed that, obesity had strong association with insulin resistance $(p=0.92)$ in first degree relatives ${ }^{13}$. A study of 154 healthy glucose tolerant first degree relatives, found absolute hyperinsulinemia and higher prevalence of insulin resistance in obese first degree relatives, as compared to non-obese relatives ${ }^{11}$. Another study, showed higher prevalence of insulin resistance, in obese first degree relatives (43.87\%) than in controls (15.2\%), as per waist hip ratio estimation ${ }^{10}$. Whereas a study at Poland, has shown that insulin resistance was present even in young lean subjects were at a high risk to develop type 2 diabetes. Thus suggesting that, insulin resistance may be a primary abnormality, in the pathogenesis of this disease ${ }^{10}$.

However, the same study on a larger population, may throw light on the exact prevalence of insulin resistance in offspring's of type 2 diabetics. It may also provide additional information, of association of insulin resistance with obesity.

\section{REFERENCES:}

1. Snehalatha C, Satyavani K, Sivasankari S, Vijay V, Ramachandran A. Diabetes Res ClinPract. 2005 Aug;69(2):205-6.

2. Kumar A, Tewari P, Sahoo SS, Srivastava AK.Prevalence of insulin resistance in first degree relatives of type- 2 diabetes mellitus patients: a prospective study in north Indian population. Indian J ClinBiochem. 2005 Jul;20(2):10-7

3. National Diabetes Data Group. Classification and diagnosis of diabetes mellitus and other categories of glucose intolerance. Diabetes 1979; 28: 1039-57.

4. Brekke HK, Jansson PA, Månsson JE, Lenner RA. Lifestyle changes can be achieved through counselling and follow-up in first-degree relatives of patients with type 2 diabetes. J Am Diet Assoc. 2003 Jul;103(7):835-43.

5. Petersen KF, Dufour S, Feng J, Befroy D, Dziura J, Dalla Man C, et al. Increased prevalence of insulin resistance and nonalcoholic fatty liver disease in Asian-Indian men. ProcNatlAcadSci U S A. 2006 Nov 28;103(48):18273-7. 
6. Costa A, Rios M, Casamitjana R, Gomis R, Conget I.High prevalence of abnormal glucose tolerance and metabolic disturbances in first-degree relatives of NIDDM patients. A study in Catalonia, a Mediterranean community. Diabetes Res ClinPract. 1998 Sep;41(3):191-6.

7. Mastsude M, Defronzo R.A. In vivo measurement of insulin sensitivity in humans. Clinical research in Diabetes and obesity. 1997;1:23-65.

8. Emoto M, Yoshiki N. Homeostasis model assessment as a clinical index of insulin resistance in Type-2 diabetic patients treated with sulfonylureas. Diabetes Care 1999; 22: 818-22.

9. Keskin M, Kurtoglu S, Kendirci M, M. EmreAtabek, Yazici C. Homeostasis model assessment is more reliable than the fasting glucose/insulin ratio and quantitative insulin sensitivity check index for assessing insulin resistance among obese children and adolescents. Pediatr 2005; 115 (4): e500-503.

10. Straczkowski M, Kowalska I, Stepień A, Dzienis-Straczkowska S, Szelachowska M, Kinalska I et al. Insulin resistance in the first-degree relatives of persons with type 2 diabetes. Med SciMonit. 2003 May;9(5):CR186-90.

11. Volk A, Renn W, Overkamp D, Mehnert B, Maerker E, Jacob Set al. Insulin action and secretion in healthy, glucose tolerant first degree relatives of patients with Type-2 diabetes mellitus. Influence of body weight. Exp Clin Endocrinol Diabetes 1999; 107(2): 140-7.

12. Isomaa, BO, Peter A, Lathi K. Cardiovascular morbidity and mortality associated with the metabolic syndrome. Diabetes Care 2001; 4: 83-9.

13. Osei K, Cottrell DA, Adenuwon CA, Ezenwaka EC, Akanji AO, O'Dorisio TM.Serum insulin and glucose concentrations in people at risk for type II diabetes. A comparative study of African Americans and Nigerians. Diabetes Care 1993; 16(10): 1367-75.

14. Matthews DR, Hosker JP, Turner RC. Homeostasis model assessment: Insulin resistance and $\beta$-cell function fasting plasma glucose and insulin concentration in man. Diabetologia 1985; 28: 419-21.

\section{AUTHORS:}

1. Arathi Darshan,

2. Vikas Patil

3. Yeshvant $\mathrm{G}$

\section{PARTICULARS OF CONTRIBUTORS:}

1. Professor. Department of Medicine JNMC, KLE University, Belgaum, Karnataka, India.

2. Senior Resident. Department of Medicine JNMC, KLE University, Belgaum, Karnataka, India.

3. Senior Resident. Department of Neurochemistry JNMC, KLE University, Belgaum, Karnataka, India.

\author{
NAME ADDRESS EMAIL ID OF THE \\ CORRESPONDING AUTHOR: \\ Dr. Arathi Darshan, \\ Prof Dept of Medicine, \\ J.N. Medical College, \\ KLE University Belgaum, Karnataka, India. \\ E-mail: arathidarshan14@rediffmail.com
}

Date of Submission: 25/03/2013.

Date of Peer Review: 25/03/2013.

Date of Acceptance: 19/04/2013.

Date of Publishing: 08/10/2013 